International Journal of

Advanced Science and Convergence

\title{
Adjustable Drawing Table and T-Square Rack with Lock
}

\author{
Reynaldo G. Salamat ${ }^{1}$, Allen N. Maroma ${ }^{2}$ \\ ${ }^{1}$ Bulacan State University, College of Industrial Technology, Philippines \\ ${ }^{2}$ Bulacan State University, College of Industrial Technology, Philippines
}

\begin{abstract}
Background/Objectives: The focus of this paper is to develop an Adjustable Drawing Table and T-square Rack with Lock that can secure the t-squares, triangles and other drawing materials that draftsman, architects, and engineers used in making plates and plans. Methods/Statistical analysis: The rack's structure consists of 40 sets of bended plain sheet panels. The first 20 panels have a length of $0.80 \mathrm{~m}$ while the remaining 20 has a length of $0.50 \mathrm{~m}$. All panels have the same width which is $0.20 \mathrm{~m}$. It has a frame with length of $2.30 \mathrm{~m}$. The T-square rack can be converted into a table. The table is made up of ply board with a thickness of $3 / 4$ and $1.10 \times 0.78 \mathrm{~m}$ in size. There are two tables located behind the rack. Findings: It has two drawers that can accommodate 40 pcs. triangle. It has a wing nut that serves as a lock when rotating the table at different angle. Improvements/Applications: A removable table top when it is not needed and detachable second rack from its main rack.
\end{abstract}

\section{Index Terms}

Adjustable, Lock , Rack, T-square Rack

\footnotetext{
Corresponding author : R.G. Salamat

reynaldo.salamat@bulsu.edu.ph

- Manuscript received January 23, 2020.

- Revised February 17, 2020 ; Accepted March 20, 2020

- Date of publication March 31, 2020.

(c) The Academic Society of Convergence Science Inc.

2619-8150 @ 2019 IJASC. Personal use is permitted, but republication/redistribution requires IJASC permission.
} 


\section{INTRODUCTION}

State Colleges and Universities in the Philippines offered a courses like Engineering and Architecture and Drafting Technology. [1] Drafting is the most important chore in these courses, therefore it is essential to maintain the quality of the drawing tools. But then how will the maintenance of these tools such as T-squares and triangles are going to be observed? Students who are taking drawing subject should be responsible to their belongings since they are the possessors of it. Professors are also liable to teach students of the proper caring of the drawing tools and storage in view of the fact that it will be used in their subject. Though, in some cases, there will be unavoidable instances that drawing tools can be damaged or lost. In Engineering and Architecture, students often carry their drafting tools to school because there is no sufficient storage available in rooms. On the other hand, [2] Drafting Technology professors think of some ways to have storage space for $\mathrm{T}$-square in each room so the students will no longer bring their tools on a daily basis. In some rooms, triangles are also kept by the professors to avoid damage and loss when the students are not using it. Henceforth, there are problems that one can see in these storages. Predominately because the $\mathrm{T}$-squares are in one place (T-square rack); there are times that the students switching their $\mathrm{T}$-squares with the other students'. There are probabilities that the T-square could be distorted and stolen by other students. Another difficulty is the lack of drawing tables use by the students when they are doing their activity drawing (plates). The enrolled student is increasing but the number of drawing table is not sufficient to answer the needs of the users. Remember that a drawing table is an important equipment to place their paper to execute a drawing.

The researcher thinks an extraordinary and useful project that contributes to the welfare of the students. Since T-Square is a universal drawing tool, we need $\mathrm{t}$ a thorough analyze on how to can keep the quality of T-squares, protect it from getting damaged, and keep away from thievery[3].

$\mathrm{T}$-square rack is perfect as a case for a $\mathrm{T}$-square. It is a framework usually made to store and secure $\mathrm{T}$ squares. Certain studies made a lot of innovation regarding $\mathrm{T}$-square racks. There goes a fixed framework made from bars and pegs for additional security. An invention with integrated lock and a wheel for easy mobilization already took its way to a new face under industrial designing[4]. And more twists are made to it to make it more functional. A rack that can turn into table and has a triangle drawer is far different in other rack.
Now, it is time to put up the newest design for its rack and provide a maximum security, functionality, and aesthetics when it comes to cost-effective intention.

The main objectives of this study were to develop an effective, durable and safe to use an Adjustable Drawing Table and T Square rack with lock.

Specifically, it has the following objectives:

1. Design an adjustable drawing table and $\mathrm{T}$ squares rack with lock to avoid losing and damaging of the drawing tools .

2. Construct an adjustable drawing table and $\mathrm{T}-$ Square rack with lock using available local materials;

3. To evaluate the acceptability of the Adjustable Drawing Table and T-square Rack with Lock in terms of:

Safety;

Functionality;

Durability;

User-friendliness;

Cost-effectiveness;

Aesthetic

\section{Methodology}

This part of the study focused on the different methods and processes employed in the construction of the project. The concept of the study was illustrated through a paradigm presented in Figure 1 with the Input, Process and Output.

The Input frame of the study consist of Ideas taken online, books, unpublished thesis and articles, Interviewing and materials, tools and equipment[5]. The Process frame is about the different processes used like Designing, Estimating, Fabricating, Testing and Evaluating of the said project. The Output frame is the finished project known as an Adjustable Drawing Table and T-Square with Lock.

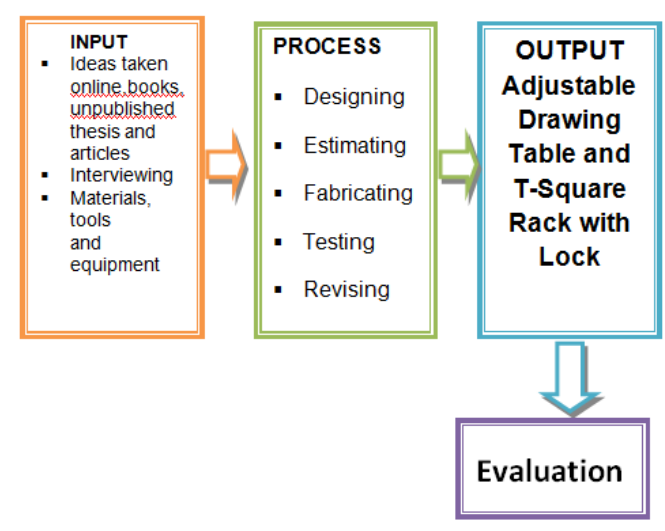

Fig. 1. Conceptual Framework 


\section{Project Description}

The purpose of the research project is to give students not only a T-square rack but a much safer rack which can also be use as table with a drawer for triangle as well.

The project is made from materials such as tubular iron with thickness of 1", the project's base has the height of $0.77 \mathrm{~m}$ and $0.15 \mathrm{~m}$ for its width, and the two racks in the project have the length of $2.22 \mathrm{~m}$ and $2.18 \mathrm{~m}$ which both have the same $0.20 \mathrm{~m}$ as their width. The panels used are made from plain sheet of metal ,the total numbers of these panels are forty (40), the first twenty (20) with $0.80 \mathrm{~m}$ length are for the T-square with 36" inches and the other twenty (20) with $0.50 \mathrm{~m}$ as length is for the 24 " T-squares, both panels have the width of $0.20 \mathrm{~m}$, the rack is not really needed to follow the assigned $\mathrm{T}$-square size because both rack can carry either the 24 " or the 36 " T-squares, it has a ply board attached to another black tubular iron to serve as a table, the table measures $1.10 \mathrm{~m} \times 0.78 \mathrm{~m}$, that can be rotated with the use of the volt swing, the project also has a drawer for triangles that is located below the table, rollers with stoppers are fastened to the stand to make the entire project movable and stop easily, the size of the entire rack is around 2.30 meters and has the height of $493 / 4$ inches.

The researcher used rivets, a metal pin for passing through holes in two or more plates or pieces to attach the panels to the tubular bars.

The T-square rack with integrated lock has 4 parts one (1) T-square rack with $0.80 \mathrm{~m}$ length two (2) Tsquare rack with $0.50 \mathrm{~m}$ as length three (3) two table with size of $1.10 \mathrm{~m} \times 0.78 \mathrm{~m}$ each four (4) triangle drawer that prevents the triangle from falling.

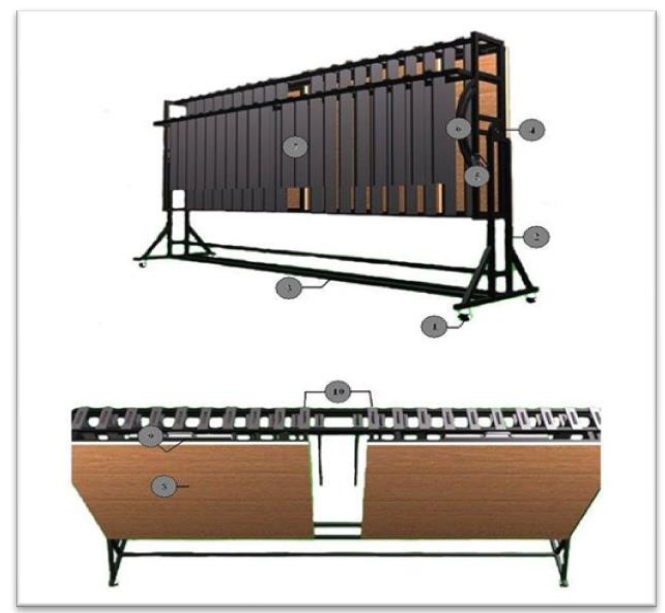

Fig. 2. Project structure

Rivets, bolts and nuts are used for the attachment of the panel in the tubular, the metal in the project is welded in an Arc Welding, the table used is made from ply board, the paints are applied twice, the first is the primer and the one is for the final color. The four (4) parts of the project are:

(1) T-square rack with $0.80 \mathrm{~m}$ length - is made from plain sheet metal that is shaped accordingly with the T-square's size, having allowance to allow it to fit perfectly.

(2) T-square rack with $0.50 \mathrm{~m}$ as length - also made from plain sheet metal and is shaped with the appropriate size for the fitting of the T-square.

(3) Two (2) tables - each one is made from ply board with the size of $1.10 \mathrm{~m} \times 0.78 \mathrm{~m}$, the table is covered by Removable, Peel \& Stick Wallpaper.

(4) Triangle drawer - is made from plywood and metal, and is placed right under the table.

\section{Project Capabilities}

The project is created with the use of solid and firm materials for a long time used purpose, this rack can be placed within classrooms of drafting, engineering and architecture, and this can also be used in offices or firms that use drawing material such as the T-square and triangle, the rack can contains up to forty (40) T-squares, the container of each $\mathrm{T}$-square is made from metal, making it strong and not bendable with these, the T-square is safe from breakage, unintentional bent, and worse torn into pieces, the rack also has a chain in its design to separate each T-squares, preventing it to be easily stolen, the table/rack can be rotated or adjust its angle up to 270 angles, the table's surface is flat and good for big or small sizes of plates or paper, the triangle may be placed in the drawer that is added under the table, in using this projects, not only the students gets a $\mathrm{T}$-square rack with a safer features it also can be their alternative drawing table if ever the tables are not equal to the number of students inside the classroom. [6] This rack enables it to have both $\mathrm{T}$-square rack and table in one single project, the table with its capability of being rotated allows itself to be easily put away or set in one place providing a bigger space for walking through or putting other drawing materials. The stand of the project also has a roller in it to enable it to be transferred from place to place [7].

\section{Projects limitation}

The researcher made the rack for forty (40) $\mathrm{T}$ squares only, that is suitable for one section only, the tables in the racks are only two (2), allowing only two (2) students to use them, the rack does not have a container for paint bottles or tubes in its design, the project even with its ability to become a table is not suited to be used in wet places or kitchen. The Tsquare rack does not have its own chair for its table; the project is heavy not suited to operate or carried alone. 


\section{RESULTS AND DISCUSSION}

The main objectives of this study was to develop an effective, durable and safe to use an Adjustable Drawing Table and $\mathrm{T}$ Square rack with lock. In order to test and assess the acceptability of the developed project, selected CIT faculty members, and drafting students were asked to evaluate the project in terms of the following parameters.

Security. Adjustable Drawing Table and Tsquare Rack with Lock was tested its security capacity to secure and protects the drafting tools from being damaged got a mean of 4.48 which is "Highly Acceptable".

Provide convertible rack. (1) the frame can be transformed into a table, the ability of the rack to be converted into a table got a mean of 4.71 which is "Highly Acceptable". While item (2) two the Tsquares are held properly and with safety. The structures of the project that enable the T-squares to be held safety got a mean of 4.47 which is "Highly Acceptable". On the other hand, item (3) three, the table is manageable and easy to use, the placing of a volt swing enables table to be easily rotated making it manageable and easy to use got a mean of 4.14 which is "Very Acceptable". Lastly item (4) four, the size of the table is appropriate for writing and drawing. The table's size is enough for either big or small types of papers that are appropriate for both writing and drawing got a mean of 4.53 which is "Highly Acceptable". The total means for the criteria "to provide a convertible rack" is 4.46 which is "Highly Acceptable.

Provide an appropriate storage for Drafting tools[8]. In item (1) one, the T-square lock secures the tools properly. The presence of the lock in the design of the project allows the rock to secures the tools properly got a mean of 4.31 which is "Highly Acceptable". In item (2) two, the drawer for the triangles is properly attached to the rack. The drawer is made lightly making it attachable or easy to place in the rack got a mean of 4.28 which is "Highly Acceptable". The overall mean for the project's criteria to provide an approximate storage for the drafting tools got a total mean of 4.30 which is "Highly Acceptable".

Provide an instant option whenever there are insufficient tables. In item (1) one the table has an easy access. Providing that the table have a volt swing to make it rotate in any degree allows table is easy to be placed got a mean of 4.03 which is "Very Acceptable". The second item (2) two the table is properly movable. The tables are screwed properly to the rack and can be removed if not needed making it movable got a mean of 4.01 which is "Very Acceptable".. In item (3) three Tables are flat and appropriate for drawing. The tables are carefully smoothened with the use of sandpaper making it flat and appropriate for drawing purpose got a mean of 4.41 which is "Highly Acceptable". The overall total mean for the projects to provide an instant option whenever there are insufficient tables got a mean of 4.15 which is Very Acceptable .

User-friendliness [9]. In item (1) one the project is easy to operate. The whole project is properly designed and created accurately making the whole project easy to operate got a mean of 3.95 which is "Very Acceptable". While Item (2) two the other part of the project can be rotated to avoid being the source of accidents. The rack together with the table attached to it is properly screwed to the volt swing allowing it to be rotated avoiding it to became the source of accident got a mean of 4.15 which is "Very Acceptable". In Item (3) three the project are already fixed and don't have to be assembled. The projects major parts are securely connected to the base, not requiring any assembling got a mean of 3.70 which is "Very Acceptable". The overall total for the project's User-friendliness got a mean of 3.93 which is "Very Acceptable".

Durability[10]. In item (1) one the base can support the entire project. The base is Made from iron tubular that is strong enough to handle the entire project got a mean of 4.34 which is "Highly Acceptable". In Item (2) two the rack and the other parts are properly built. The rack and the other parts are properly welded got a mean of 4.22 which is "Highly Acceptable". In Item (3) three the wheels have a stopper to enable fastening the object in a particular place. The project has wheels with stopper that allows it to be fastened or place anywhere. In Item (4) four the chains used are working to ensure that it can be a safe panel for the T-squares. The chains that are used in the project are all new and are surely working making the panels safer for the Tsquares got a mean of 4.32 which is "Highly Acceptable". The overall total of the projects in terms of Durability got a total mean of 4.30 which is "Highly Acceptable".

Functionality. In item (1) one the project has no problem when being used. The project is tried and used and there is no problem in the process got a mean of 4.22 which is "Highly Acceptable". In Item (2) two the wheels in both sides are properly working. The wheels both move properly got a mean of 4.38 which is "Highly Acceptable". In Item (3) three the table is usable. The table can be used anytime and is easy to use got a mean of 4.48 which is "Highly Acceptable. For Item (4) four the object can hold triangles in it. The project has two drawers that can hold the triangles within it got a mean of 4.50 which is "Highly Acceptable" to the respondents. In Item (5) five The T-squares are fully secured from being stolen and damaged. The $\mathrm{T}$-squares security is proven to work and prevents the tools to being stolen or damaged. The overall mean according to 
Functionality got a total mean of 4.41 which is "Highly Acceptable" .

Cost-effectiveness. In item (1) one the object is marketable. The materials used are searched properly to make sure that the object may be bought in a reasonable price got a mean of 4.03 which is "Very Acceptable" to the respondents. The overall total of mean for Cost-effectiveness is 3.95 which is "Very Acceptable.

Safety. In item (1) one the absence of toxic materials. The paints that are used in the project does not have any toxic materials in their composition making it safer got a mean of 3.64 which is "Very Acceptable". The second item (2) two the absence of sharp edges and joints. The projects panels are folded properly to prevent it from having sharp edges and the joints are attached correctly got a mean of 3.87 which is "Very Acceptable". The overall total mean for the projects Safety is 3.76 which is "Very Acceptable."

\section{CONCLUSION}

Based on the findings of the study, the following conclusions are drawn:

1. The project secures and protects the T-squares from damaging and losing it table.

2. The project can be converted into a drawing

3. The project serves as storage for drawing tools such as T-squares and triangles.

4. The project is easy to operate.

5. The project is made from iron tubular and galvanized plain sheet that makes it strong enough for long term use.

6. The project is safety to use and no harmful chemical found on it.

\section{RECOMMENDATIONS}

Based on the evaluation conducted by the researcher, the following recommendations are drawn:

1. The evaluator advised to used aluminium and stainless steel in the base and stand of the project to prevent rust when it contact to moisture or air.

2. The project need to replaced the existing plastic roller, instead used metal ball caster to bring the heavy load and make it easy in transferring from one placed to another.

\section{ACKNOWLEDGMENT}

This work was supported in part by the College of Industrial Technology, Department of Drafting and Digital Graphic Technology.

\section{REFERENCES}

[1] Johnson, T. W. (1921) Combined Drawing Board and Instrument Case. Retrieved August 2015 from Patent Website: https://www.google.com /patents/US1369439

[2] Fazio Jr. J.D. (1984). Case for draftsman. Retrieved August 2015 from Patent Website: http://www.google.com/patents/US4475650

[3] Beaton. Sr P.J., Wallis, V. B. (1975). Desk-top drafting table. Retrieved August 2015 from Patent Website:http://www.google.com/patents/ US3872800

[4] Technical drawing tool. Retrieved August 2015 from Wikipedia, the free encyclopaedia Website: https://en.wikipedia.org/wiki/Technical _drawing_tool

[5] Towne, E. (1877). Patent model for parallel rule and T-square. Retrieved August 2015 from American History Website: http:// americanhistory.si.edu/collections/search/object/ nmah_690213

[6] Folding Ruler. (2015). Retrieved August 2015 from ebay Website: http://www.ebay.tv/sch /Collectibles-/1/i.html?_sop=23...folding+rulers

[7] Storage \& Holding. Retrieved 26 September 2015, from the media journal Website: http://www.themhedajournal.org/content/3q04/st oragehandling.php

[8] Morle, K. A.(2006).Multispiral DVD/CD rack. Retrieved 26 September 2015, from Patent Website: http://www.google.com/patents/ US7083052

[9] Sahli, F. (1978). Drafting Table. Retrieved 26 September 2015, from Patent Website: http://www.google.com/patents/US4099469

[10] Nusbaum, N. H., Levy, F. A. (2006). Bicycle rack anti-sway stabilizer. Retrieved 26 September 2015, from Patent Website: http://www.google.com/patents/US6988645 